\title{
Estudio de un caso de mutismo selectivo: evaluación e intervención en el contexto escolar
}

\author{
Sergio Balbuena Teruel \\ Inmaculada Rueda Lozano \\ C. E. I. P. Juan Cano (Melilla)
}

\author{
Paz López Herrero \\ Universidad de Granada \\ Campus de Melilla
}

\section{RESUMEN}

Los niños con mutismo selectivo presentan un complejo conjunto de síntomas y no sólo se niegan a hablar en situaciones sociales concretas a pesar hacerlo en otras, sino que en ellos también se observa timidez, ansiedad, sobreprotección familiar y/o bilingüismo.

Se presenta el caso de un varón de 8 años de edad con mutismo selectivo, escolarizado desde los 3 años y que no hablaba en el colegio. El objetivo era establecer la comunicación oral del alumno en el entorno escolar con distintas personas y en diferentes situaciones.

Las técnicas de terapia de conducta empleadas fueron: relajación y respiración, desvanecimiento estimular, automodelado y reforzamiento positivo.

La aplicación del programa resulta positiva porque el alumno comienza a hablar con diferentes personas en su centro escolar. Se recomienda seguir trabajando ciertos aspectos porque el niño sólo habló una vez a su tutora y con una alta activación muscular y autonómica.

Palabras clave: Ansiedad, bilingüismo, mutismo selectivo, sobreprotección familiar, técnicas de terapia de conducta, timidez

\section{ABSTRACT}

Children with selective mutism present a complicated set of symptoms, as they not only refuse to speak in certain social situations (e.g. at school), despite talking in others, but also appear shy and anxious, and often suffer problems associated with overprotective families and/or bilinguism.

In this case we have studied an 8-year-old male with selective mutism, who has attended school since he was 3 years old and does not speak at school. The objective was to enable the child to communicate orally with different people in different settings at the school.

We used behavioural therapy techniques such as: Relaxation and breathing techniques, stimulus fading, self modeling and positive reinforcement.

The treatment program was very positive because the boy has now begun to speak to different people at the school. Nevertheless we recommend that more work be done because the pupil only spoke to his teacher once during which he was in a state of high muscle and autonomic activation.

Keywords: Anxiety, behavioral therapy techniques, bilinguism, overprotective families, selective mutism, shyness

\footnotetext{
Sergio Balbuena Teruel, C. E. I. P. Juan Caro, Melilla; Inmaculada Rueda Lozano, C. E. I. P., Melilla; y Paz López Herrero, Departamento de Personalidad, Evaluación y Tratamiento Psicológicos, Universidad de Granada, Campus de Melilla. Agradecimientos a Antonio María Santos Ortega, Nigel Walkington y Barbara Young por las correcciones al manuscrito. Correspondencia: Paz López Herrero. Departamento de Personalidad, Evaluación y Tratamiento Psicológicos. Facultad de Educación y Humanidades. Carretera Alfonso XIII. 52005 Melilla. Teléfono: 952698 734. Correo electrónico: pazlopez@ugr.es
} 
En la delimitación operativa del mutismo selectivo se constata un descenso hasta su anulación del habla en situaciones sociales concretas y ante personas ajenas al ámbito íntimo. Sin embargo, no existen otros problemas psicológicos o somáticos que expliquen tal situación. Además, suele aparecer y relacionarse con el inicio del período escolar y puede mantenerse varios años (Olivares, Rosa, \& García-López, 2002; Ponzurick, 2012). Por último, la alteración interfiere el rendimiento escolar, laboral o la comunicación social (Barbero Las Heras, Maroto, \& Fernández, 1994; Busse \& Downey, 2011; Fernández \& López-Herrero, 2000; Kearney \& Vecchio, 2007; López-Herrero, 2000).

El lugar, las personas y las actividades tienen una gran importancia en la evaluación. Esto es, los mutistas tienden a hablar en casa y no fuera de ella (lugar), suelen hacerlo más con otros niños que con adultos, en la escuela los primeros que les suelen oír expresarse son los extraños y el profesor es el último al que el niño habla, pues aquel representa una figura de autoridad, es quien le evalúa (personas) y, por último, es probable que hable en situaciones agradables en las que en el pasado solía hacerlo (actividades) (McHolm , Cunningham, \& Vanier, 2005).

Es importante establecer un diagnóstico diferencial dado que en diferentes trastornos se pueden observar problemas en la comunicación social e incapacidad para hablar adecuadamente en situaciones sociales. Por lo tanto, el mutismo selectivo debe distinguirse de (Kristensen, 2000; Kristensen, 2002): a) Los trastornos del habla, puesto que la alteración del lenguaje oral no se limita a una situación social específica. b) Las dificultades que presentan los niños procedentes de familias que han emigrado a un país donde se habla una lengua diferente y que pueden rehusar hablar el nuevo idioma por falta de conocimiento del mismo.c) Los sujetos con trastorno generalizado del desarrollo, esquizofrenia u otro trastorno psicótico, o retraso mental grave.

Desde un punto de vista conductual son las hipótesis que relacionan ansiedad, refuerzo y mutismo las más contrastadas. De hecho cuanto más se refuerza el mutismo más difícil es extinguirlo (Krysanski, 2003). El trastorno se mantendría por el comportamiento similar de padres o parientes próximos (Kristensen, 2002; Olivares, Maciá, \& Méndez, 1993a).

Por otro lado, Echeburúa y Espinet (1997) plantean que, a pesar de que con su mutismo el niño puede obtener algunos reforzadores positivos (ser el centro de atención, ser tratado de forma especial,...), esta conducta está mantenida por algún factor inhibidor de la emisión de voz probablemente de tipo cognitivo. Y así, consideran el mutismo como una conducta de evitación mantenida por reforzadores negativos de tipo cognitivo "no hablar para evitar algo que teme"; estas expectativas negativas, consideradas y vividas como peligrosas, conllevan un incremento del miedo respecto de las mismas. De igual modo, contribuyen al mantenimiento de la ausencia del habla al disminuir y/o evitar el estado de malestar subjetivo y proporcionar privilegios y atención. También el uso de modos alternativos de comunicación perpetúan dicha conducta anómala (López Herrero, 2000). 
Asimismo, en estos pequeños son frecuentes ciertas características personales, destacando la timidez, el retraimiento, la terquedad y algunos rasgos obsesivos (Busto, 1998; Cohan, Price, \& Stein, 2006; Zelenko \& Shaw, 2000).

Además, en la base del problema se encuentran factores como la sobreprotección materna, los trastornos del lenguaje y del habla, el retraso mental, la hospitalización, los traumas antes de los 3 años de edad o la inmigración como factor estresante muy relacionado con las demandas lingüísticas. En este sentido, las familias con niños mutistas has sido descritas como más aisladas y tímidas, con fuertes lazos entre madres e hijos, que causan problemas de separación e individualización (Sharkey \& Mc Nicholas, 2008). Más específicamente, Hayden (1980) habla del Mutismo Simbiótico para describir la estrecha relación que en ocasiones existe entre los padres y los hijos y recomienda una intervención familiar en este tipo de casos.

Haciendo hincapié en las diferencias étnico-culturales o posible efecto del bilingüismo Cohan et al. (2006), Elizur y Perednik (2003), Fernández y López-Herrero (2001), Gallardo y Gallego (1995), McHolm et al. (2005), Sharkey y McNicholas (2008) y Toppelberg, Tabors, Coggins, Lum, y Burger (2005) manifiestan que el mutismo es más probable cuando: 1 ) La conducta de no hablar es desproporcionada en relación al conocimiento/exposición de la nueva lengua. 2) Está presente en ambos idiomas. 3) Se acompaña de ansiedad y timidez ante nuevas situaciones. 4) El bilingüísmo, el temperamento inhibido, la inmigración y el estrés son factores que interactúan en la adquisición de otra lengua.
Si se sostiene que el miedo a hablar es una respuesta de ansiedad y que su mantenimiento viene dado por la confirmación de sus expectativas (pensamientos) respecto de las situaciones y personas temidas, las técnicas utilizadas en el tratamiento son las derivadas del condicionamiento clásico y del modelo cognitivo-conductual, como la respiración y la relajación, las habilidades sociales, el modelado, el automodelado filmado y el automodelado gradual filmado-trucado (Beare, Torgenson \& Creviston, 2008; Grover, Hughes, Bergman, \& Kingery, 2006; Sharkey \& Mc Nicholas, 2008).

El tratamiento se habrá de dirigir a producir cambios concretos en el comportamiento de los adultos que conviven o mantienen una relación muy frecuente con el niño (profesores, compañeros, padres), así como del propio niño, si fuera preciso; pero, nunca sólo en el comportamiento del niño. Es así que, en ocasiones, en las intervenciones la familia también ha sido incluida, obteniéndose unos resultados espectaculares. Cabe recordar que la familia, al igual que los compañeros de clase, barrio o autobús, puede ser clave en todo tratamiento que persiga la generalización; además, el problema remite con mayor rapidez cuando se trata en el medio en el que surge (Fisak, Oliveros, \& Ehrenreich, 2006; Lazarus, Gavilo, \& Moore, 1983; Olivares et al., 1993a; Olivares, Rosa, \& Olivares, 2007; Omdal, 2008; Sharkey, McNicholas, Berry, Begley, \& Ahern, 2008).

El pronóstico respecto a la eficacia de la intervención empeora si se demora su aplicación debido al grado de consolidación del aprendizaje (Olivares, 1998) y también si, aun siendo sometido a tratamiento, el sujeto se aproxima 
a los diez años de edad sin que se haya producido un incremento sustancial de la conducta de hablar. Hay que destacar que pese a que el trastorno se presenta entre los 2 y los 5 años de edad el tratamiento no comienza hasta más tarde, alrededor de 6-8 años, pues existe desinformación que conlleva el pensar que el niño es tímido, creencias erróneas por parte de los profesionales y padres e incluso conductas similares en el ámbito familiar del sujeto (Kristensen \& Torgersen, 2001; Ponzurick, 2012). De tal manera que no es extraño observar un retraso en el inicio de este tipo de intervenciones (Sharkey \& Mc Nicholas, 2008).

\section{Método}

\section{Participantes}

B es un niño de 8 años de edad, español, cuyos padres son de origen marroquí. Está escolarizado desde los 3 años en un Centro Público y en la actualidad cursa $2^{\circ}$ curso de Educación Primaria. Fue su profesor de Educación Infantil quien informó al Equipo de Orientación Temprana de que el alumno no hablaba en el colegio. De este modo, durante dos años, profesor y equipo mantuvieron reuniones periódicas para analizar la evolución del alumno y poner en práctica algunas pautas de actuación para impulsar su comunicación oral. Entre estas últimas se planteó realizar actividades grupales para que participara en ellas, mejore su confianza y se comunique oralmente o evitar situaciones que conllevaran aislamiento. Tras dicho espacio de tiempo y dada la persistencia de sus problemas se decide realizar una valoración psicopedagógica. Esta preocupación es compartida por la madre de B, quien informa a la tutora actual de que su hijo sólo habla con los miembros del núcleo familiar más cercano, mostrándose esquivo con otros familiares (abuelos, tíos, etc.) y vecinos.

\section{Evaluación y diagnóstico}

Instrumentos. El principal obstáculo con el que se encontró el equipo de orientación a la hora de evaluar a B fue su negativa a participar en dicho proceso al no responder ante las instrucciones dadas. Este hecho impidió la aplicación directa de las pruebas estandarizadas habituales para la evaluación de los distintos aspectos del desarrollo. Por lo tanto, los instrumentos finalmente utilizados y especialmente diseñados para la exploración del caso son los que se exponen en la Tabla 1.

\section{Datos derivados del proceso de evaluación}

Información familiar. El núcleo familiar está compuesto por los padres y dos hermanos más de 13 y 12 años de edad. La madre no comenta ningún dato sobresaliente relacionado con el desarrollo del niño, excepto en el ámbito de la adquisición del lenguaje que, al compararlo con el de sus hermanos, fue algo tardío. Asimismo, reconoce una cierta sobreprotección familiar y así, ante la timidez del hijo, es aquella quien suele responder por él. Sin embargo, también admite su severidad cuando $B$ se niega a comunicarse con los demás. La madre se muestra inquieta en las entrevistas y su actitud inicial de colaboración (por ejemplo siguiendo las pautas dadas por el terapeuta) se transforma, posteriormente, en hostilidad hacia todo lo que tenga que ver con el centro escolar. Cabe destacar que en casa los padres 
Tabla 1

Instrumentos de evaluación

\begin{tabular}{|c|c|c|}
\hline & Instrumento empleado & Área de información \\
\hline \multirow{4}{*}{$\begin{array}{l}\text { Información } \\
\text { escolar }\end{array}$} & $\begin{array}{l}\text { Registro de observación de conductas del } \\
\text { alumno en el aula }\end{array}$ & $\begin{array}{c}\text { Lenguaje } \\
\text { Socialización }\end{array}$ \\
\hline & Escala del nivel de competencia curricular & Competencia curricular \\
\hline & $\begin{array}{l}\text { Entrevista a tutora/ maestros implicados } \\
\text { en el proceso de enseñanza del alumno }\end{array}$ & $\begin{array}{c}\text { Lenguaje } \\
\text { Socialización } \\
\text { Estilo aprendizaje }\end{array}$ \\
\hline & $\begin{array}{l}\text { Registro de observación de conductas del } \\
\text { alumno en el recreo }\end{array}$ & $\begin{array}{c}\text { Lenguaje } \\
\text { Socialización } \\
\text { Motora } \\
\end{array}$ \\
\hline \multirow{3}{*}{$\begin{array}{l}\text { Información } \\
\text { familiar }\end{array}$} & $\begin{array}{l}\text { Grabación del alumno jugando con sus } \\
\text { hermanos en casa }\end{array}$ & $\begin{array}{c}\text { Lenguaje } \\
\text { Socialización }\end{array}$ \\
\hline & Entrevista a la madre del alumno & $\begin{array}{c}\text { Anamnesis } \\
\text { Lenguaje } \\
\text { Socialización }\end{array}$ \\
\hline & Informes médicos: ORL, oftalmólogo & Salud \\
\hline
\end{tabular}

emplean tanto la lengua materna (tamazight) como el castellano, aunque éste no lo dominan completamente.

Nivel de desarrollo. El oftalmólogo recomienda a los padres que $B$ utilice gafas debido a su miopía y al estrabismo convergente de su ojo izquierdo. En lo que concierne al ámbito comunicativo-lingüístico se sirve de gestos corporales y ruidos, solamente lo hace con ciertos compañeros y, siempre, en grupos reducidos. Rechaza cualquier tipo de interacción con los adultos poco conocidos que se dirigen a él, así se observan conductas de evitación como uso de signos para comunicarse o tono de voz bajo y conductas de escape como no mirar a la cara del interlocutor. Incluso la interacción oral con los miembros de su familia, aparentemente normal en la grabación aportada por la madre es inexistente ante la presencia de una persona ajena. En este mismo aspecto $y$, tras analizar el video grabado en su casa, se constatan errores articulatorios como rotacismo, simplificación de sinfones y sustituciones de fonemas que no son estables, es probable que esto último sea debido a un incorrecto asentamiento del léxico. Predominan las oraciones simples, los errores en el orden de los elementos y la omisión de artículos y nexos. Se constata la utilización de ciertos vocablos en tamazight. Desde un punto de vista pragmático en la grabación se aprecia un uso del lenguaje con distintas funcionalidades: Interactiva e informativa, al comunicarse con su madre para contarle lo que está haciendo. Imaginativa, al hablar mientras juega con sus muñecos sobre una situación irreal. Regulado$r a$, dando instrucciones al hermano sobre las normas del juego. Además, su voz tiene un timbre especialmente infantil, es demasiado aguda, su ritmo de emisión es acelerado, aparece una tensión excesiva y episodios disfémicos. 
En cuanto a su desarrollo motriz, se advierte cierta pérdida de equilibrio y torpeza motora, se cae con frecuencia en el recreo. En el aspecto psicológico, $B$ es un niño muy apegado a la madre, con la que pasa la mayor parte del tiempo. Presenta altos niveles de ansiedad en situaciones interpersonales, que se manifiesta en activación muscular y autonómica con tensión corporal y facial, hiperventilación y aumento de la tasa cardiaca. Sus cogniciones son de miedo e inseguridad a la hora de hablar y las expectativas de profesores, compañeros y padres acerca del problema son negativas. En el aspecto motor aparece negación a hablar, risa exagerada y descontrolada, tics nerviosos como guiño de ojos y colocación de la mandíbula inferior hacia delante, dientes apretados, estrabismo convergente más notable, ausencia de contacto físico con maestros y compañeros, restricción de las relaciones sociales en el entorno escolar, deficiencias en el control de la defecación, episodios de disfemia, conductas de escape (no mirar a la cara del interlocutor) y evitación (uso de signos para comunicarse). Por otro lado, se muestra muy reacio a relacionarse con adultos que no conoce, este rechazo se plasma en su expresión facial que es de desinterés y repulsión.

Competencia curricular. La tutora informa de que el alumno no muestra interés hacia las tareas escolares y tiene un importante desfase curricular, no alcanzando los objetivos básicos de la etapa de Educación Infantil. Sin embargo, los maestros que intervienen en su aprendizaje afirman que $B$ tiene una capacidad que no se corresponde con sus bajos resultados o calificaciones y ello debido a que todo trabajo escolar le exige un cierto intercambio oral de modo que al no hablar su aprendizaje se ve limitado. En lo referido al estilo de aprendizaje, la maestra destaca que el niño se inhibe ante las actividades verbales, mejorando en las manipulativas, no le motivan las tareas escolares, la relación con compañeros y maestros es escasa, no participa en actividades de grupo y prefiere trabajar de forma individual.

\section{Conclusión diagnóstica}

Todos estos datos parecen confirmar que $B$ presenta un mutismo selectivo. De este modo, y tomando en consideración los rasgos diagnósticos proporcionados por la American Psychiatric Associacion (APA, 2002), donde se contemplan como criterios claves:

a) Una incapacidad persistente para hablar en situaciones sociales específicas (en las que se espera que hable. Por ejemplo, en la escuela) a pesar de hacerlo en otras situaciones.

b) La alteración interfiere el rendimiento escolar o laboral o la comunicación social.

c) La duración de la alteración es de por lo menos 1 mes (no limitada al primer mes de escuela).

d) La incapacidad para hablar no se debe a una falta de conocimiento o de fluidez del lenguaje hablado requerido en la situación social.

e) El trastorno no se explica mejor por la presencia de un trastorno de la comunicación (ejemplo: tartamudez) y no aparece exclusivamente en el transcurso de un trastorno generalizado del desarrollo, esquizofrenia u otro trastorno psicótico. 
Más concretamente, y como causas que explican este diagnóstico, se ha de mencionar en este caso los factores siguientes (Beare et al., 2008; Cohan et al., 2006; Grover et al., 2006; Olivares et al., 2007; Sharkey \& Mc Nicholas, 2008; Zelenko \& Shaw, 2000):

- Timidez excesiva en las relaciones interpersonales.

- Altos niveles ansiedad.

- Sobreprotección familiar, especialmente de la madre.

- Bilingüismo mal integrado, de forma que no se siente totalmente competente en castellano.

\section{Tratamiento}

El plan de intervención logopédica planteado se inicia cuatro años más tarde de que se detectara el mutismo selectivo de B. De acuerdo con las recomendaciones del Equipo de Orientación, el alumno ha recibido en el centro educativo apoyo especializado por parte de un maestro especialista en Pedagogía Terapéutica y otro en Audición y Lenguaje ( $A$ y $L)$. Sin embargo, B sigue sin hablar y rechaza el contacto con los demás en el entorno escolar, lo cual se refleja en el importante desfase curricular ya comentado.

\section{Objetivos}

El fin último del programa de intervención era establecer la comunicación oral del alumno en el entorno escolar con sus compañeros y profesores. La consecución de este objetivo obligó a plantear la adquisición de otros requisitos previos que podrían resumirse en los siguientes:
- Reducir la ansiedad del alumno a la hora de hablar en el centro escolar.

- Ampliar las habilidades comunicativas y sociales del alumno para que se expresara oralmente en el colegio con distintas personas en diferentes situaciones.

\section{Técnicas}

En el tratamiento se utilizaron diferentes técnicas conductuales que se describen a continuación (Barbero Las Heras et al., 1994; Beare et al., 2008; Fisak et al., 2006; Olivares, Méndez \& Maciá, 1993b; Olivares, 2005; Olivares et al., 2007; Olivares, Rosa, Piqueras \& Sánchez, 2006):

- Respiración y relajación: se aplicó la técnica de la Tortuga ideada por Scheider y Robin (Gil \& Miranda, 2000) para reducir la activación neurovegetativa y muscular observada en B cuando tenía que hablar en el colegio. Y, posteriormente, la técnica de relajación de Jacobson (Escudero, 2006; Payne, 2009).

- Desvanecimiento estimular: que consiste en la transferencia del control estimular a través de la atenuación del estímulo discriminatorio. Se utilizan personas con las que se habla en un contexto determinado introduciéndolas en situaciones en las que usualmente no se comunicaba oralmente. En este caso, por ejemplo, $B$ jugaba con determinados alumnos con los que manifestaba mayor afinidad en el aula de A y L. Con las personas se actuó del mismo modo, esto es, ir hablando con otros niños con los que no lo hacía.

- Automodelado: se puso en práctica el 
automodelado gradual a partir de grabaciones filmadas y trucadas. La corta edad del niño permitió realizar montajes audiovisuales creíbles en los que aquel aparecía hablando ante personas con las que no lo hacía. La técnica de automodelado incluye la exposición gradual simbólica y en vivo, el manejo de contingencias, la transmisión de información y la implicación grupal e institucional. Está destinado a niños pequeños cuyas habilidades cognitivas no les permiten discriminar entre la ficción y la realidad.

- Reforzamiento positivo: como complemento a las técnicas anteriores se proporciona un evento valorado como positivo por el mudo selectivo (sonrisa, afirmaciones verbales,...) de una forma contingente e inmediata al habla.

Para garantizar el correcto desarrollo del programa de intervención se evitó presionar al niño para que hablara, se le hacía notar lo importantes que eran sus avances pero se actuaba con total normalidad cuando se comunicaba oralmente (sin exagerar sus logros) y se plantearon sesiones lúdicas y atractivas.

\section{Temporalización}

El plan de tratamiento fue diseñado para un curso académico (de septiembre a junio). Se planteó en tres fases de una duración trimestral que, posteriormente, se fueron adaptando a las demandas reales de la intervención. El paso de una fase a otra se realizó en función del logro de los objetivos propuestos.

\section{Fases}

\section{Primera fase}

Objetivo: Proporcionar al alumno estrategias que incrementen su seguridad en situaciones comunicativas, reduciendo de forma progresiva la ansiedad y el rechazo que éstas le generan.

Esta fase la llevó a cabo el maestro de A y L en su aula específica en dos sesiones semanales de 20 minutos de duración. En ella, se solicita a un alumno muy cercano al niño, Zacarías, que jugara con $B$ en dicha clase. Con ello empieza la aplicación del desvanecimiento estimular ya que la intervención, en un primer momento, implicó al compañero con el que el alumno se comunicaba por medio de gestos y con el que se manifestaba cómodo realizando un juego que le gustaba.

Durante este periodo se realizaron dos tipos de actuaciones:

Relajación y respiración: Se comenzó con la práctica de la técnica de la Tortuga, pues la pretensión era que el alumno controlara las respuestas psicofisiológicas que se desencadenaban ante situaciones que para él eran negativas, en este caso la incomodidad que le provocaba estar en un contexto que le obligaba a emplear el lenguaje oral. Dicha técnica usa la analogía de una tortuga que se repliega dentro de su caparazón cuando se siente amenazada ante determinados estímulos ambientales. Así, se le enseña que al oír la palabra clave "tortuga" debía encogerse y controlar sus impulsos y emociones. Más tarde se pedía a $B$ y a Zacarías que pensaran en esa palabra cuando algo empezara a "no ir bien" y actuaran tal y como se les había enseñado. Una vez que 
este aspecto se interiorizó, se profundiza en técnicas de relajación basadas en la tensióndistensión progresiva, concretamente se utilizó el método de Jacobson. El alumno debía aplicar esta nueva forma de relajación en cuanto detectara una señal de alarma dado que la respuesta de distensión era incompatible con la excesiva activación que experimentaba al tener que hablar en público.

Actividades lúdicas. Bingo: También se plantearon diferentes juegos basados en la interacción comunicativa. Entre ellos, sobre todo se utilizó, por su excelente acogida, "el bingo de las imágenes", que era una adaptación del tradicional bingo numérico. En él, cada alumno (B y Zacarías) tenía un cartón de ocho casillas referido a una categoría semántica. De un saco se iban sacando tarjetas/imágenes y los participantes señalaban las casillas que se correspondían con la tarjeta extraída. Al principio juegan los niños y el terapeuta, pero siempre dirigidos por este último. Sin embargo, rápidamente los niños se van desenvolviendo solos sin dificultad.

El uso de este tipo de actividad viene dado por la sencillez de la misma, rasgo elegido intencionadamente al pretender anular cualquier tipo de dificultad que se sumara a la problemática del alumno y porque a $\mathrm{B}$ le agradaba mucho y permitía trabajar el lenguaje oral al tener que denominar las tarjetas que se iban escogiendo.

\section{Segunda fase}

Esta fase se desarrolló del mismo modo que la anterior. En ella se llevaron a cabo intervenciones con grupos reducidos de 40 minutos de duración así como sesiones individuales de 20 minutos.

\section{A) Sesiones en pequeños grupos}

Objetivos: a) lograr la expresión oral del alumno con sus compañeros en el aula de A y $L, y$ b) proporcionar a los demás niños estrategias correctas para hablar con B.

En las sesiones se continúa utilizando el desvanecimiento estimular de personas. Así, $\mathrm{B}$ acudía al aula de $A$ y $L$ junto a cuatro compañeros de su clase, entre los que se encontraba Zacarías, pues era con este con el que el niño ya hablaba. Los alumnos eran elegidos por la tutora en función de su buen comportamiento en clase, lo que hacía que este método fuera evaluado por todos los participantes, incluido el alumno, como muy positivo y motivador. En cada sesión parte del grupo iba siendo renovado por nuevos compañeros.

Las técnicas y actividades planteadas fueron las que se exponen a continuación:

Automodelado filmado y trucado: Se aplicó la técnica del automodelado gradual filmado y trucado por medio de un montaje de vídeo y audio. En la cinta aparecía el alumno realizando distintas actividades escolares, por ejemplo: haciendo su tarea y aparentemente respondiendo a su tutora y compañeros ante preguntas del tipo ¿Con qué amigos te gusta jugar? Este método sirvió para modelar la conducta verbal del niño pero, también, como exposición ante el terapeuta al estar este presente y oírle hablar cuando se emitían los vídeos (Grover et al., 2006).

Al inicio de la sesión se explicaba que se tenía preparada una sorpresa. Creada la expectación inicial se reproducía el montaje durante 5 
minutos. Una vez visto, se analizaban durante 15 minutos más las actuaciones de los niños. El fin era que sus compañeros vieran que $B$ hablaba y que mostraran su alegría cuando lo hacía con el fin de ayudarle a sentirse más cómodo (refuerzo positivo contingente). Principalmente se pretendía que el alumno alcanzara una mayor seguridad hacia el acto de hablar.

Durante la exposición, el pequeño recibió refuerzos sociales vicarios consistentes en verbalizaciones del adulto significativo al que no se habla (tutor) mediante voz en off durante la grabación y refuerzo social real por parte de los compañeros y del terapeuta (ejemplo: $\mathrm{i} B$ habla!) (Olivares et al., 2007).

Bingo de imágenes: Inicialmente, el maestro de $A$ y $L$ realizaba el reparto de los grupos. Luego, eran los propios niños los que se distribuían. Fue muy significativo observar cómo todos los alumnos querían formar parte del grupo de $\mathrm{B}$ al considerarlo un experto en dicha actividad. Para poder jugar se formaban dos agrupaciones y el quinto alumno se encargaba de sacar y denominar las fichas extraídas. En ningún momento el pequeño quiso asumir este papel. Por dicho motivo, se graba a $B$ evocando todas las palabras del bingo y en la siguiente sesión grupal no se utilizó el saco de las palabras, sino tal grabación. Para todos resultó muy divertido oír la voz de su compañero en el ordenador "cantar" las palabras del bingo. Incluso el alumno también disfrutó de la novedad introducida. En algunas sesiones se volvía a recurrir al saco de las palabras y le se pedía a B que dijera en voz alta las tarjetas seleccionadas.
Las sesiones descritas se grabaron para utilizarlas en el tratamiento individual que se pasa a describir con más detalle.

\section{B) Sesiones individuales:}

Objetivos: a) fomentar el uso de las técnicas de relajación, b) analizar su comportamiento verbal y no verbal para que la comunicación fuera más efectiva, c) mejorar su autoconcepto en relación al hecho de que era capaz de hablar en el colegio con sus compañeros, y d) Evaluar su lenguaje.

A continuación se comentan las estrategias utilizadas:

Relajación y respiración: De nuevo se puso en práctica la relajación muscular progresiva de Jacobson.

Más tarde, se dedicaron 10 minutos a ver fragmentos de los vídeos de las sesiones grupales. El objetivo era analizar su expresión oral e introducir las modificaciones pertinentes no solo para ir mejorando su comunicación, sino para que B se sintiera capacitado para hacerlo al recordarle que ha de utilizar, entre otras, pautas específicas que reducen su nivel de activación: hablar en estado de relajación, respirar profundamente por la nariz ,...

Evaluación del desarrollo lingüístico: Dado que el alumno ya hablaba con el maestro de $\mathrm{A}$ y $L$, este realizó una valoración más exhaustiva de su lenguaje. Con tal motivo empleó la prueba ELCE-R (López et al., 2007). De los cuestionarios que incluye dicha prueba se utilizaron todos los relativos a la elocución, el test de madurez de Hildreth y Griffith y el cuestionario de valoración del nivel verbal puro (basado en el cuestionario de Terman Merrill). Tal evaluación se distribuyó en cuatro sesiones de 30 minu- 
tos de duración. Dos de ellas se centraron en la exploración de la elocución y, otras dos, de la comprensión.

\section{Tercera fase}

Objetivos: a) generalizar la conducta de hablar con sus compañeros de clase en su aula, b) comunicación verbal ante su tutora, y c) mayor autocontrol psicofisilógico, superación de la ansiedad, progreso en las habilidades de comunicación.

Esta última fase se planificó en dos sesiones semanales de 40 minutos de duración y se extendió hasta la finalización del curso escolar. Prioritariamente se dedicó a la generalización al entorno de la clase de los logros alcanzados hasta el momento. El fin último era que el alumno fuera tanto social como educativamente incluido en el contexto escolar (Omdal, 2008).

El punto de partida fue el bingo en imágenes por tratarse de una de las actividades claves del programa de intervención. La elección respondía a que había sido el único juego en el que $B$ había hablado con sus compañeros. Por otro lado, la dinámica de dicha diversión era totalmente conocida por todos alumnos $\mathrm{y}$, especialmente por $\mathrm{B}$, con lo que el grado de malestar ante un posible fracaso por desconocimiento quedaba anulado. Asimismo, se hizo coincidir los campos semánticos tratados en el bingo con la temática específica que se estaba abordando en clase (ejemplo: los transportes, los animales, etc).

En el bingo de imágenes primero participaron todos los niños coordinados por el maestro de A y L. Más tarde, además, intervino la tutora del grupo.

\section{Contexto de clase con todos los alumnos}

Los alumnos se dividen en cuatro grupos y se les asignan los cartones del bingo. Cada equipo tenía un representante que era el encargado de acercarse al saco de las palabras, custodiado por el maestro de A y L, extraer una ficha del campo semántico sobre el que trataba el juego y decirla en voz alta para que los equipos la señalasen en caso de tenerla. En estos primeros momentos no se le pide a $B$ que adopte ese papel ni tampoco él lo solicita. Nuestra pretensión era que se familiarizara con la nueva situación hasta lograr que estuviera lo suficientemente cómodo como para participar totalmente en el juego. Pasadas tres semanas, el maestro de A y L le invitó a ser el portavoz de su equipo. No siempre se insistió en que adoptara el papel de representante porque podía suponer un retroceso en los avances alcanzados.

\section{Contexto de clase con todos los alumnos}

\section{y la tutora}

Después de seis semanas, la tutora formó parte de las situaciones comunicativas.

Por lo tanto, se realizaron sesiones grupales en las que se incluyó a tal profesora de modo que durante dos semanas, ésta participó en la actividad como si fuera un miembro más de uno de los equipos. Pero nunca formó parte del grupo de B. Tras dicho periodo, la tutora pasó a integrase en el equipo del niño.

Asimismo, se retomaron las sesiones individuales de autocontrol psicofisiológico y de análisis de la conducta. Por un lado, se recuperaron las técnicas de relajación y respiración resaltando la importancia de respirar adecuada- 
mente y de atraer a su mente las sensaciones de comodidad. Por otro, se veían las grabaciones de las partidas realizadas en clase para que $B$ avanzara en el autocontrol de las situaciones temidas (hablar estando presente la tutora). En las cintas de esta fase tercera se analizaron aquellos momentos en los que el alumno aparecía más retraído, era entonces cuando el maestro-terapeuta le proponía preguntas que implícitamente le invitaban a reflexionar sobre su comportamiento y le ofrecía alternativas a sus actuaciones: "¿Por qué te quedaste callado?, ¿no sabías el nombre de la ficha? Acuérdate de mirar a la persona con la que hablas, cuida el tono de tu voz, habla alto y claro".

\section{Resultados}

Antes de comenzar la intervención B no se expresaba oralmente, ni se relacionaba o participaba en actividades grupales en el colegio. Solo con un compañero de su aula se comunicaba utilizando para ello gestos y ruidos. Se mostraba muy ansioso cuando tenía que interactuar con personas ajenas a su círculo familiar más cercano. Además, su interés por las actividades escolares era escaso. Por tales motivos, la evaluación del desarrollo de su lenguaje oral no pudo llevarse a cabo al no poder administrarle pruebas estandarizadas $\mathrm{y} / \mathrm{o}$ no estandarizadas que le exigían una respuesta oral.

Cuando se pone en práctica el programa de tratamiento se observa una evolución en $B$ en el sentido de que comienza a hablar con diferentes personas en su centro escolar.

Fase primera. La aplicación de técnicas de control psicofisiológico así como la utilización de situaciones comunicativas lúdicas a través de juegos como el bingo permitieron reducir significativamente el elevado nivel de ansiedad del alumno.

El desvanecimiento estimular dio lugar a que comenzara a hablar por primera vez

con alguien ajeno al núcleo familiar en el contexto escolar. Especialmente la introducción del compañero, con quien en un principio se relacionaba por medio de gestos, resultó todo un éxito. En esta fase B conversaba animada y más cómodamente con Zacarías y con el maestro-terapeuta en el aula de $A$ y $L$ (ejemplo: ¡Mira, Zacarías, este animal del dibujo!).

Fase segunda. Tanto el automodelado como el uso adecuado de los refuerzos potenciaron la expresión oral de B. La primera técnica, porque modelaba su habla y en ella el alumno se exponía al terapeuta dado que en las cintas trucadas aparecía el niño hablando directamente con su tutora en el colegio. La segunda, porque los compañeros de clase cuando le oían hablar en el vídeo denotaban su alegría con aplausos, sonrisas y con exclamaciones de júbilo. Esto es, le administraban refuerzos positivos contingentes a la conducta de hablar en el centro escolar. Además, el terapeuta contribuía en este mismo sentido, administrando refuerzos sociales tanto al niño como al resto del alumnado.

Las intervenciones en pequeñas agrupaciones favorecieron que el alumno ampliara su círculo social y se relacionara con otros niños. De hecho, cada vez eran más los compañeros de su clase con los que jugaba e interactuaba en el aula de $A$ y $L$, en el patio. Concretamente, durante los recreos B jugaba con otros pequeños y se divertía participando en distintas 
actividades. También, en una ocasión accedió a cantar ante los demás niños del grupo las fichas que iba sacando del saco de las palabras. Aunque ayudado por otro compañero, con una voz muy débil y excesiva rapidez. El resto del alumnado celebró con gran entusiasmo este primer avance.

Por tanto, se constata que en el aula de A y L el lenguaje oral empieza a estar cada vez más presente en su relación con los iguales y son más numerosas las producciones espontáneas del tipo ¡bien! ¡huy! o correcciones hechas a otros niños cuando se equivocan al jugar.

Las sesiones individuales de relajación sirvieron para que $B$ se mostrara calmado cuando hablaba con los otros pequeños, para tener más control y seguridad ante el acto de hablar. Igualmente, estos logros se vieron impulsados por las normas concretas de actuación que el terapeuta le daba cuando se revisaban los vídeos.

Poco a poco, sus intervenciones mientras veía las grabaciones iban automatizando y nuestras preguntas iban más dirigidas al acto comunicativo para seguir modelando su expresión y comunicación oral.

Todo ello contribuyó a que el niño variara su autoconcepto, sintiéndose capaz y con estrategias suficientes para expresarse oralmente ante sus compañeros y el terapeuta en el aula de Ay L.

En este momento el alumno hablaba con el maestro-terapeuta y con algunos de sus compañeros, pues se dirigía más a los varones de su clase, aunque siempre en pequeños grupos y en el aula de $A$ y $L$, controlaba, en cierta medida, su alto nivel de ansiedad y participaba cada vez más en actividades grupales.
En relación a la evaluación del desarrollo lingüístico, la prueba ELCE-R ofrece los siguientes resultados:

Elocución: A) Exploración anatómica y funcional de los órganos fono- articulatorios: se observa una oclusión dental defectuosa y la falta de piezas dentarias definitivas. B) Exploración fonológica inducida y repetida: se evidencian dificultades en los fonemas /q/ y /ř / y en los grupos consonánticos o sinfones. Además, se comprueba que $B$ suele omitir la primera sílaba de la palabra, las consonantes al final de la palabra y de sílabas mixtas. C) Discriminación auditiva: presenta dificultades en la discriminación fonética de algunos los sonidos consonánticos /ř/ /l/, /g//x/, /s//q/.

Comprensión: De la valoración léxico-semántica y del razonamiento verbal de las respuestas de $B$ se desprende un cierto retraso que es más significativo en las pruebas que comprometen el ámbito expresivo (razonamiento verbal). Específicamente, las respuestas relativas a definiciones de absurdos y semejanzas se corresponden con las de un niño de 5 años de edad.

Por tanto, estos datos confirman un desfase lingüístico importante, vinculado claramente a su privación voluntaria del uso del lenguaje oral y a que en el hogar se utilizaba otra lengua.

Fase tercera. Es de destacar que $B$, en un primer momento, no quiso voluntariamente ser el portavoz de su equipo. Evitaba con esta conducta el tener que decir en voz alta, delante de todos sus compañeros y en su aula la ficha del bingo. Si bien, seguía jugando con entusiasmo y se alegraba cuando su equipo 
tenía las tarjetas nombradas celebrando con aplausos y gestos de alegría los logros de su equipo cuando iba tachando las casillas del cartón. Después, el terapeuta lo seleccionó como representante de su grupo. Pero se negó a nombrar la tarjeta. Finalmente, en una ocasión se acercó con decisión a la bolsa de las palabras, sacó la ficha y delante de sus compañeros dijo el nombre del objeto al que aludía. No obstante, su voz era casi inaudible, no miró al resto del alumnado y se giró hacia el maestro de $A$ y $L$ para hablar. En días posteriores su implicación aumentó y se encargaba de denominar las imágenes. Sin embargo, aunque contestaba, seguían restringidos su tono de voz, su mirada y sus gestos.

Cuando la tutora comienza a participar en el bingo de las palabras, en $B$ se apreció una reducción de su expresión oral. $Y$, también, un aumento de su actividad muscular y autonómica, la aparición de tics nerviosos (guiño de ojos, avance de mandíbula, etc.) que prácticamente habían desaparecido en las fases anteriores. Sin embargo, seguía muy interesado jugando. A partir de este momento, una sola vez consiente en ser el portavoz de su equipo y denomina la ficha.

Al constatar la inquietud del pequeño se le recuerdan las técnicas de relajación y se analizan las grabaciones realizadas en su clase. Ambas técnicas permitieron al pequeño tomar conciencia del problema y poner en práctica tales estrategias cuando se comunicaba con compañeros y profesores.

Por último, se ha de manifestar que está fue una fase de evolución muy lenta y que pese a los logros señalados, el objetivo general del programa de intervención no había sido alcanzado completamente.

\section{Discusión}

Con este programa de intervención se pretendía establecer la comunicación oral del alumno en el entorno escolar con distintas personas y en diferentes situaciones. Lo cual obligaba a reducir su ansiedad y a ampliar sus habilidades comunicativas. Se ha de recordar que las intervenciones de caso único se muestran como apropiadas a la hora de evaluar la eficacia de los tratamientos conductuales (Beare et al., 2008; Kristensen \& Torgersen, 2002).

Los recursos empleados con éxito en el caso presentado se enmarcan dentro de la terapia de conducta. De modo que se han puesto en práctica tanto técnicas operantes (desvanecimiento estimular, reforzamiento positivo) como las basadas en el condicionamiento clásico y en el modelo cognitivo conductual (relajación y respiración, automodelado) (Barbero Las Heras et al., 1994; Beare et al., 2008; Grover et al., 2006; Olivares, 2005; Olivares et al., 1993b; Olivares et al., 2007; Olivares et al., 2006; Sharkey \& Mc Nicholas, 2008). Más específicamente como viene a continuación.

Primera fase. Se subraya la importancia de integrar en la intervención, desde inicio de la misma, a un compañero cercano al alumno (Zacarías), así como la utilización de recursos lúdicos atrayentes (bingo de palabras). Ambas estrategias, conjuntamente con la puesta en práctica de la técnica de la tortuga y de la relajación de Jacobson, permitieron lograr los objetivos propuestos en este momento del tratamiento. 
Además, se destaca el hecho de que $B$ habla con el terapeuta desde el primer momento en que comienza a jugar con él al bingo y ello debido a que no lo ve como profesor o figura de autoridad que le evalúa sino como un compañero más que participa con él en distintas actividades (McHolm et al., 2005).

Segunda fase. Se acentúa lo efectivo que resultó combinar sesiones en pequeños grupos con intervenciones individuales y la utilización de las técnicas de automodelado filmado y trucado, de desvanecimiento estimular de personas y de refuerzo positivo para alcanzar las metas planteadas, es decir: lograr la expresión oral del alumno con sus compañeros y maestro-terapeuta en el aula de $A$ y $L$ de forma que aquel hable con mayor comodidad, mejore su autoconcepto y se pueda realizar una evaluación de su lenguaje. Igualmente, los demás alumnos reforzaron correctamente a $B$ y variaron el concepto que de él tenían, percatándose de que era capaz de hablar en el colegio.

Tercera fase. Una de las principales claves en los avances que experimentó $B$ se basó en el uso del desvanecimiento estimular de personas y situaciones. En este momento tal técnica permitió que en su clase el niño se comunicara oralmente con sus compañeros y, en una ocasión, con su tutora.

Asimismo, resalta la gran utilidad del bingo como recurso didáctico acomodando las imágenes a los temas que se estudiaban en clase. Igualmente, dicha similitud de contenidos permitía ver de un modo natural la presencia del maestro-terapeuta en el aula usual. El interés primordial fue normalizar al máximo la situa- ción de intervención para fomentar la generalización de la conducta objetivo.

La valoración general de la aplicación del programa resulta positiva, aunque no todas las metas planteadas fueron conseguidas plenamente. En concreto, existen dos aspectos que exigen una continuación y/o una adaptación del programa de tratamiento:

- Si bien se redujo el alto grado de ansiedad del alumno en la clase de $A$ y $L$, este objetivo no llegó a ser generalizado al contexto de su aula.

- B sólo habló una vez a su tutora y en un estado de alta activación muscular y autonómica. Sin embargo, el que lo hiciera revela que este objetivo se encuentra en un momento inicial de su consecución.

La posible explicación de estos últimos datos podría residir en la consolidación del problema debido al retraso en el inicio del tratamiento (Kristensen \& Torgersen, 2001; Olivares, 1998; Ponzurick, 2012; Sharkey \& Mc Nicholas, 2008). Asimismo, el éxito total de ambos aspectos estuvo directamente limitado por el factor tiempo. Esto es, requería de un tiempo mayor al planificado inicialmente en el programa puesto que el ritmo de evolución de un tratamiento lo marca el propio alumno en función de sus circunstancias personales (momento, intervención, edad,...).

Tal y como proponen Beare et al. (2008) una de las dificultades observadas es que el niño extienda los aprendizajes a otros lugares y personas y hable con diversos compañeros y profesores. En esta línea, sería interesante plantearse un programa educativo que incluyera a los padres del niño con el propósito de que 
aprendieran a actuar con efectividad en situaciones cotidianas, a apoyarle adecuadamente en el entorno escolar cuando se enfrenta a personas desconocidas. El objetivo final sería la generalización completa del tratamiento establecido; esto es, que el alumno hablara con diferentes personas en distintos ambientes. Además, con este tipo de intervenciones también se consigue que los padres se apoyen, pues en ocasiones las familias se sienten aisladas, desconsoladas. Incluso muchos cónyuges llegan a culparse mutuamente de la conducta del hijo, sobre todo cuando aparecen en ellos conductas similares de ansiedad social o de mutismo previo (Kristensen \& Torgersen, 2001). En resumen, se cree que un factor importante en el éxito de estos casos es la introducción de las familias en la intervención (Olivares et al., 2006; Sharkey et al., 2008).

Como se ha reflejado anteriormente, tras evaluar el desarrollo del lenguaje de $B$, se constata un retraso lingüístico en todos los componentes y dimensiones del lenguaje. Tal demora estaría ligada a su escasa comunicación oral y al bilingüismo mal integrado de su hogar. Conviene recordar que el lugar idóneo para impulsar el lenguaje es el colegio, sin embargo el alumno no habla en el centro escolar y, por lo tanto, los distintos profesionales no le pueden corregir. Por otro lado, dichas correcciones tampoco se realizan en casa ya que la familia no domina completamente la segunda lengua (Fernández \& López-Herrero, 2001; Gallardo \& Gallego, 1995; López-Herrero, 2000).

Siguiendo esta misma línea, no es extraño observar en estudios a largo plazo que los índices de habla de estos niños permanecen por debajo de la media. Y que si bien son adultos continúan teniendo ciertas dificultades de comunicación (Chavira, Shipon-Blum, Hitchcock, Cohan, \& Stein, 2007; Sharkey \& McNicholas, 2008).

\section{Referencias}

American Psychiatric Associacion. (2002). Manual diagnóstico y estadístico de los trastornos mentales ( $4 .^{\text {a }}$ ed., texto rev.) (T. de Flores, J. Toro, J. Masna, J. Treserra, É. Masana, \& C. Udina, Trads.). Barcelona: Masson (Trabajo original publicado en 2000).

Barbero Las Heras, F. Maroto, G., \& Fernández, A. (1994). Tratamiento conductual en el colegio del mutismo electivo de una niña de cinco años. Análisis y Modificación de Conducta, 20, 899-921.

Beare, P., Torgenson, C., \& Creviston, C. (2008). Increasing verbal behavior of a student who is selectively mute. Journal of Emocional and Behavioral Disorders, 16, 248-255. doi: 101177/1063426608317356

Busse, R., \& Downey, J. (2011). Selective Mutism: A three-tiered approach to prevention and intervention. Contemporary School Psychology, 15, 53-63. doi: 892429277.

Busto, M. C. (1998). Manual de logopedia escolar. Niños con alteraciones del lenguaje oral en Educación Infantil y Primaria. Madrid: CEPE.

Cohan, S., Price, J., \& Stein, M. (2006). Suffering in silence: Why a developmental psychopatohology perspective on selective mutism is needed. Journal Developmental and Behavioral Pediatrics, 27, 341-355. doi: 0196206X/06/2704-0341

Chavira, D., Shipon-Blum, E., Hitchcock, C., Cohan, S., \& Stein, M. (2007). Selective mutism and social anxiety disorder. American Academy of Child and Adolescent Psychiatry, 46 (11), 1464-1472.

Echeburúa, E., \& Espinet, A . (1997). Tratami- 
ento en el ambiente natural de un caso de mutismo electivo. En F. X., Méndez \& D. Maciá (Ed), Modificación de conducta con niños y adolescentes (pp. 423-440). Madrid: Pirámide.

Elizur, Y., \& Perednik, R. (2003). Prevalence and description of selective mutism in immigrant and native families: A controlled study. Journal American Academy of Child and Adolescent Psychiatry, 42, 1451-1459. doi:10.1097/01.chi.000091944.28938.c6

Escudero, M. (2006). Técnicas de relajación y autocontrol emocional. Curso práctico. Madrid: TEA.

Fernández, A., \& López-Herrero, P. (2000). Mutismo electivo: programa de intervención. En Actas del IX congreso INFAD 2000. Infancia y adolescencia (pp. 553-557). Cádiz. INFAD.

Fernández, A., \& López-Herrero, P. (2001). Doble tratamiento en un caso de mutismo electivo. En I Jornadas de intercambio de experiencias educativas (pp. 29-37). Granada: Grupo Editorial Universitario.

Fisak, B., Oliveros, A., \& Ehrenreich, J. (2006). Assessment and behavioral treatment of selective mutism. Clinical Case Studies, 5, 382402. doi: $0.1177 / 1534650104269029$

Gallardo, J., \& Gallego, J. (1995). El niño que no habla. En J. R. Gallardo, \& J. L. Gallego, Manual de logopedia escolar. Un enfoque práctico (pp. 267-281). Málaga: Aljibe.

Gil, M. D., \& Miranda, A. (2000). La hiperactividad y el déficit atencional. En M. C. Fortes, A. Ferrer, \& M. D. Gil, Bases psicológicas de la Educación Especial. Aspectos teóricos y prácticos (pp. 261-288). Valencia. Promolibro.

Grover, R., Hughes, A., Bergman, R., \& Kingery, J. (2006). Treatament modifications based on childhood anxiety diagnosis: Demonstrating the flexibility in manualized treatment. Journal of Cognitive Psychotherapy: An International Quarterly, 20, 275-286.

Hayden T. (1980). The classification of elective mutism. Journal of the American Academy of Child and Adolescent Psychiatry, 19, 118133.

Kearney, C., \& Vecchio, J. (2007). When a child won't speak. The Journal of Family Practice, 56, 917-921.

Kristensen, H. (2000). Selective mutism and comorbility with developmental disorder/ delay, anxiety disorder and eliminitation disorder. Journal of the American Academy of Child and Adolescent Psychiatry, 39, 249256.

Kristensen, H. (2002). Non-specific markers of neurodevelopmental disorder/delay in selective mutism: a case-control study. European Child and Adolescent Psychiatry, 11, 71-78.

Kristensen, H., \& Torgersen, S. (2001). MCMI-II personality traits and symptom traits in parents of children with selective mutism: a case-control study. Journal of Abnormal Psychology, 110, 648-652. doi:10.1037//0021843X.110.4.648

Kristensen, H., \& Torgersen, S. (2002). A casecontrol study of EAS child and parental temperaments in selectively mute children with and without a co-morbid communication disorder. Nordic Journal of Psychiatry, 56, 347-353.

Krysanski, V. (2003). A brief review of selective mutism literature. The Journal of Psychology, 137, 29-40.

Lazarus, P. J., Gavilo, H. M., \& Moore ,J.W. (1983). The treatment of elective mutism in children within the school setting: Two cases studies. School Psychology Review, 12, 467472.

López, M. J., Zurita, M. D., Redón, A. García, I., Santamaría, M., \& Iniesta, J. (2007). ELCE- R. Exploración del lenguaje comprensivo y expresivo. Madrid: CEPE.

López-Herrero, P. (2000). Un caso de mutismo electivo en el colegio. Revista de Logopedia, Foniatría y Audiología, 20, 30-36. 
McHolm, E., Cunningham, A., \& Vanier, K. (2005). Helping your child with selective mutism: steps to overcome a fear of speaking. Oakland, CA: New Harbinger Publications.

Olivares, J. (1998). Ansiedad y habla. El mutismo selectivo. En Actas del I symposium internacional sobre fobias y otros problemas de ansiedad (p. 15). Granada. Funveca y Apicsa.

Olivares, J. (2005). El niño con miedo a hablar. Madrid: Pirámide.

Olivares, D., Maciá ,J., \& Méndez, F.X. (1993a). Naturaleza, diagnóstico y tratamiento conductual del mutismo electivo. Una revisión. Análisis y Modificación de Conducta, 19, 771792.

Olivares, J., Méndez, F. X., \& Maciá, D. (1993b). Detección e intervención temprana en mutismo electivo. Una aplicación del automodelado gradual filmado y trucado (AGFT). Análisis y Modificación de Conducta, 19, 793-817.

Olivares, J., Rosa, A., \& García-López, L. (2002). Mutismo selectivo. En M. Servera (Dir.), Intervención en los trastornos del comportamiento infantil. Una perspectiva conductual de sistemas (pp. 331-357). Madrid: Pirámide.

Olivares, J., Rosa, A., \& Olivares, P. (2007). Tratamiento psicológico del mutismo selectivo. Madrid: Pirámide.

Olivares, J., Rosa, A., \& Piqueras, J. (2005). Evaluación cognitivo-conductual del mutismo selectivo. En V. Caballo, Manual para la evaluación clínica de los trastornos psicológicos (pp. 387-400). Madrid: Pirámide.

Olivares, J., Rosa, A., Piqueras, J., \& Sánchez, R. (2006). Tratamiento de un niño con mutismo selectivo. En F. Méndez, J. Espada, \& M. Orgilés, Terapia psicológica con niños y adolescentes (pp. 67-83). Madrid: Pirámide.

Omdal, H. (2008). Including children with selective mutism in mainsteam schools and kindergartens: Problems and possibilities. International Journal of Inclusive Education, 12,
301-315. doi:10.1080/13603110601103246

Payne, R. (2009). Técnicas de relajación: guía práctica para el profesional de la salud. Barcelona: Paidotribo.

Ponzurick, J. M. (2012). Selective mutism: A team approach to assessment and treatment in the school setting. The Journal of School Nursing, 28(1), 31-37. doi:10.1177/1059840511422534

Sharkey, L., \& McNicholas, F. (2008). More than 100 years of silence, elective mutism. A review of the literature. European Child and Adolescent Psychiatry, 17(5), 255-263. doi:10.1007/s00787-007-0658-4

Sharkey, L., McNicholas, F., Barry, E., Begley, M., \& Ahern S. (2008). Group therapy for selective mutism: A parents and children treatment group. Journal of Behavior Therapy and Experimental Psychiatry, 39, 538-545. doi:10.1016/j.jbtep.2007.12.002

Toppelberg, C., Tabors, P. Coggins, A., Lum, K., \& Burger, C. (2005). Differential diagnosis of selective mutism in bilingual children. Journal American Academy of Child and Adolescent Psychiatry, 44, 592-595.

Zelenko, M., \&Shaw, R. (2000). Case study:Selective mutism in an immigrant child. Clinical Child Psychology and Psychiatry, 5 (4), 555562. doi:10.1177/1359104500005004009 